\title{
DO ESPAÇO DA CONSTITUIÇÃO AO LUGAR DO ENSINO: O DIREITO FUNDAMENTAL À EDUCAÇÃ̃O E A REGULAMENTAÇÃO DO ENSINO DOMICILIAR
}

Bruno Oliveira Falcão*

RESUMO: O estudo averigua a adequação dos projetos de lei que regulamentam a educação domiciliar no Brasil ao direito à educação conforme previsto na Constituição Federal de 1988. Sendo a educação um dever compartilhado entre Estado, sociedade e família, questiona-se em quais situações a família poderia reivindicar o protagonismo do ensino. A investigação bibliográfica passa pela definição do conteúdo do direito fundamental à educação. Em seguida, analisa a intermediação pela Constituição da tensão entre as pretensões dos indivíduos e as exigências da coletividade. Finalmente, os projetos de lei 3179/2012, 2401/2019 e 3262/2019 são examinados à luz dos marcos teóricos fixados anteriormente.

PALAVRAS-CHAVE: Educação domiciliar. Família. Estado. Direito à educação. Direitos Fundamentais. Constituição.

\section{FROM THE CONSTITUTIONAL PLACE TO THE CLASSROOM: FUNDAMENTAL RIGHT TO EDUCATION AND HOMESCHOOLING REGULATION}

\begin{abstract}
The study evaluates the adequacy of the bills that propose the regulation of homeschooling in Brazil to the right to education as established in the Federal Constitution of 1988. As education is a duty shared among State, society and family, the situations in which the family may claim protagonism in teaching are questioned. The bibliographic research goes through the definition of the fundamental right to education's content. Afterwards, analysis the constitutional intermediation of the tensions between individual's intentions and collectivity's demands. Finally, the bills 3179/2012, 2401/2019 and 3262/2019 are examined, taking as parameter the theoretical framework previously outlined.
\end{abstract}

KEYWORDS: Homeschooling. Family. State. Right to education. Fundamental rights. Constitution.

\section{INTRODUÇÃO}

Ao julgar o Recurso Extraordinário n 888.815, o Supremo Tribunal Federal (2019) fixou a tese de que não "existe direito público subjetivo do aluno ou de sua família ao ensino domiciliar, inexistente na legislação brasileira”. A menção à falta de previsão normativa que possibilite a educação em casa sugere que não há incompatibilidade apriorística entre a prática e o regime constitucional do direito à educação, abrindo o caminho para a apresentação e

\footnotetext{
* Mestrando em Constitucionalização do Direito pela Universidade Federal de Sergipe. Analista do Ministério Público do Estado de Sergipe. E-mail: brunofalcao@gmail.com.
} 
reciclagem de propostas legislativas sobre a questão. Atualmente, no Congresso Nacional, os projetos em tramitação mais avançada são os de n 3179/2012, 2401/2019 e 3262/2019.

As questões levantadas por defensores e detratores do ensino domiciliar são muitas e poderiam suscitar estudos por perspectivas variadas, de modo que é virtualmente impossível encerrar toda a discussão em um único texto. A complexidade do fenômeno sugere cuidado redobrado com o recorte do tema. Com essa limitação em vista, propõe-se como problema o questionamento acerca da viabilidade da educação domiciliar face à Constituição Federal de 1988 e, em sendo viável, avalia-se em que termos essa modalidade de instrução poderia ser implementada no Brasil. De início, trabalha-se com a hipótese de que a valorização, no ordenamento jurídico brasileiro, da pluralidade de perspectivas proporcionada pelo espaço escolar relega a situações de extrema excepcionalidade a aceitação da educação ministrada em casa, o que excluiria a opção de ordem puramente ideológica.

Para verificar a hipótese é necessário traçar um perfil da relação entre direito e educação, culminando na delimitação do conteúdo do direito humano e fundamental à educação, de modo a permitir um exame de adequação constitucional das propostas a respeito da educação domiciliar que há alguns anos habitam o debate público brasileiro e, atualmente, ganham corpo no espaço institucional. Cabe, portanto, fazer um cotejo entre situações hipotéticas e os valores gravados na Constituição, definindo quais os caminhos aceitáveis.

Com essa finalidade, o tema é abordado por meio da conjugação da análise de fontes tradicionais do direito - em específico, a Constituição, leis ordinárias, normas de Direito Público Internacional, uma decisão judicial e projetos de lei em tramitação - com a adoção de literatura de referência que permite a compreensão das questões de fundo que informam a problemática. Trata-se, portanto, de estudo de revisão bibliográfica, que tem início na delimitação do conteúdo do direito fundamental à educação, avança para a análise do papel exercido pela Constituição na intermediação entre as intenções dos indivíduos e as demandas da coletividade, chegando, ao fim, à apreciação dos projetos de lei que pretendem regulamentar a educação domiciliar no Brasil sob a ótica dos marcos teóricos previamente estabelecidos.

\section{O CONTEÚDO DO DIREITO À EDUCAÇÃO}

O direito à educação é um direito humano, reconhecido expressamente na Declaração Universal dos Direitos Humanos de 1948, assim como um direito fundamental a 
que a Constituição Federal de 1988 dedica uma seção com exclusividade. Apresenta, portanto, inquestionável normatividade, mas não é o direito a qualquer educação, afinal, a "educação é necessária, mas nem toda a educação é legítima" (MONTEIRO, 2003, p. 786). Para que fundamente alguma pretensão ou resolva algum conflito, é necessário saber qual é a educação juridicamente exigível.

Agostinho dos Reis Monteiro (2003, p. 769) afirma que o direito à educação, que não é a mesma coisa que a educação, pressupõe o acesso aos fins, conteúdos e níveis definidos pelo artigo 26 da Declaração Universal dos Direitos do Homem e por seus desdobramentos em outras normas internacionais. Revela, assim, um caminho para identificar a acepção específica que a educação recebe ao constituir-se como direito. Nina Ranieri (2009, p. 271272) destaca a pluralidade de sentidos com que o termo "educação" é utilizado na Constituição brasileira como um problema conceitual e hermenêutico, que cresce em dificuldade diante da estruturação de um programa constitucional para a educação, que demanda precisão para que seja implementado. Em regra, o direito à educação é conceituado na doutrina e na jurisprudência por derivação das finalidades estabelecidas no texto constitucional, que não guardam correspondência exata com seu conteúdo.

A análise de um problema educacional pelo prisma jurídico começa, então, pela identificação do conteúdo do direito à educação, o que se faz, de início, no plano internacional e, em seguida, no ordenamento interno brasileiro, como principal referência para o enfrentamento do problema posto.

No Sistema Internacional de Direitos Humanos, o direito à educação tem como principal referência normativa o artigo 26 da Declaração Universal dos Direitos Humanos, que se divide em três parágrafos, nos quais estão previstas a gratuidade e a obrigatoriedade da instrução elementar, além da acessibilidade à educação técnica-profissional e ao ensino superior; é fixada a orientação da educação para o pleno desenvolvimento da personalidade e para o respeito aos direitos humanos e à tolerância; e é estabelecida a prioridade dos pais na escolha da espécie de instrução a que serão submetidos seus filhos.

As linhas gerais traçadas na Declaração Universal dos Direitos Humanos são detalhadas nos artigos 13 e 14 do Pacto Internacional Sobre os Direitos Econômicos, Sociais e Culturais, e nos artigos 28 e 29 da Convenção Sobre os Direitos da Criança. Com acréscimos, os diplomas internacionais mencionados reproduzem o previsto no terceiro parágrafo do artigo 26 da Declaração Universal, que tem estreita pertinência com os argumentos despendidos em favor da educação domiciliar. O que se acrescenta não é meramente 
acessório, mas, antes, essencial à compreensão do texto sintético da norma principal. No artigo 13 do Pacto Internacional Sobre os Direitos Econômicos, Sociais e Culturais é garantida a liberdade de escolha pelos pais de escolas que não sejam aquelas mantidas pelas autoridades públicas, desde que atendam aos padrões estabelecidos pelo Estado. Expressamente, exige-se que o ensino privado observe os princípios elencados no artigo, que, em linhas gerais, correspondem àqueles definidos na Declaração Universal. A diferença mais significativa entre as normas reside na previsão de liberdade de escolha entre escolas, sugerindo a restrição da opção entre gêneros de instrução àqueles que são ministrados em estabelecimentos educacionais.

Já na Convenção Sobre os Direitos da Criança, consta apenas a garantia de liberdade para a criação e direção de instituições de ensino, com o condicionante de que obedeçam aos padrões mínimos estatais. A casa, em que pese possa e deva ser um ambiente em que crianças e adolescentes são educados, não se confunde com um estabelecimento educacional, que assume características não redutíveis à transmissão de conteúdo curricular. Nos principais vértices normativos que delimitam o direito à educação no plano internacional, há um direcionamento comum da educação para o pleno desenvolvimento da personalidade humana - finalidade que, na leitura de Monteiro (2003, p. 769), resume todas as outras - e para a tolerância, o que também se faz sentir no ordenamento brasileiro, sobretudo no texto constitucional, que, entre os artigos 205 e 214, estabelece uma educação voltada para o exercício da cidadania e para a qualificação para o trabalho, sem descuidar do pluralismo de ideias.

$\mathrm{Na}$ Constituição brasileira, a educação surge no artigo $6^{\circ}$ como direito social e é posta, na seção que lhe é própria, como direito e dever. A ela, todos fazem jus; para que se realize, concorrem o Estado, a família e a sociedade. A educação, que compreende toda a formação das pessoas, não se confunde com o ensino, que corresponde ao processo formativo desenvolvido no âmbito das escolas. O ensino, assim, é espécie do gênero educação (RANIERI, 2009, p. 278).

O acesso à educação é direito público subjetivo no nível fundamental e deve ser progressivamente universalizado no ensino médio. Cabe ao estado, também, o atendimento especializado aos portadores de deficiência, preferencialmente na rede regular, o oferecimento da educação infantil em creches e pré-escolas e a garantia de ingresso no nível superior de acordo com a capacidade de cada um, como define o artigo 208. O ensino é facultado à iniciativa privada, desde que cumpra normas gerais definidas pelo Estado, que também terá a 
prerrogativa de autorizá-lo e avaliá-lo, conforme o artigo 209. Nesse ponto, a compreensão do ensino como educação formal sugere uma passagem mais estreita para a educação domiciliar do que a que foi enxergada pelo Supremo Tribunal Federal ao julgar o Recurso Extraordinário $\mathrm{n}^{\circ}$ 888.815. O texto constitucional cuida, ainda, da previsão de que seja definido conteúdo mínimo para o ensino fundamental, no artigo 210, da divisão de atribuições entre os sistemas de ensino das três esferas federativas, artigo 211, das fontes de custeio e da destinação das verbas, artigos 212, 212-A e 213, além de remeter à norma infraconstitucional a tarefa de estabelecer um plano nacional de educação decenal, artigo 214.

Destacadas as principais orientações a respeito da educação na Constituição brasileira, a colocação de algumas questões permite que o conteúdo do direito à educação alcance a clareza necessária à sua concretização. Nesse sentido, a investigação compreende a definição da titularidade, do objeto, da oponibilidade e dos meios de proteção do direito à educação (MONTEIRO, 2003, p. 767).

São titulares preferenciais do direito à educação os educandos, o que, à primeira vista, pode parecer um truísmo. Mas Estado, família e sociedade reivindicam exercer suas esferas de influência sobre a educação ministrada, respectivamente, aos seus cidadãos, aos seus filhos e aos seus membros, o que faz a questão crescer em complexidade após um olhar mais atento. Uma educação voltada para a democracia e para os direitos humanos tem repercussão sobre a coletividade, tornando indistinguíveis, nesse ponto, os interesses individuais e coletivos envolvidos (RANIERI, 2009, p. 281). Seguindo a mesma linha, Monteiro (2003, p. 766) afirma que "o conhecimento e a capacidade de exercício dos direitos de cada um, assim como a consciência do dever de respeitar os direitos dos outros, dependem da realização do direito à educação". A circunstância de a titularidade ser exercida especialmente por crianças e adolescentes, que dos adultos dependem inteiramente para a concretização do direito à educação, confere contornos imprecisos a esse vetor essencial à definição de seu conteúdo (MONTEIRO, 2003, p. 768). A confusão entre os interesses de quem é o beneficiário do direito e as pretensões de quem pode falar em nome do beneficiário está na base da problematização em torno da educação domiciliar.

A Convenção Sobre os Direitos da Criança, incorporada ao ordenamento jurídico brasileiro pelo Decreto $\mathrm{n}^{\circ} 99.710$, de 21 de novembro de 1990 , em seu artigo $3^{\circ}$, erigiu o interesse maior da criança à condição de vetor interpretativo primordial, eliminando eventual dúvida quanto à prevalência do interesse do educando sobre o de seus responsáveis. O direito à educação, portanto, pode mesmo ser exercido contra o Estado e contra a família 
(MONTEIRO, 2003, p. 769). A Constituição Federal de 1988, no artigo 227, confere prioridade absoluta à garantia de direitos de crianças, adolescentes e jovens, e o Estatuto da Criança e do Adolescente, estruturado sob nítida orientação constitucional, destrincha em direitos e deveres a priorização dos interesses de seus destinatários. O interesse superior do educando é um pressuposto ético do regime constitucional da educação, o que tem por consequência considerar o educando não apenas como o objeto da instrução, mas, sim, como o sujeito do direito à educação (MONTEIRO, 2003, p. 786).

A perspectiva do melhor interesse da criança e do adolescente, embora relevante, não alcança todos os beneficiários do direito à educação ${ }^{1}$, de modo que se destina apenas a solucionar a tensão estabelecida entre quem está submetido ao poder familiar e quem exerce esse poder. Mesmo assim, a solução é parcial e abre amplo espaço para subjetivismos voluntariosos. A definição por uma pessoa de qual é o melhor interesse de outra é sempre problemática. Se à família não é dado fazer escolhas livremente em lugar de suas crianças, que dizer do Estado ou da sociedade? O problema e sua resposta estão no advérbio e na locução adverbial, respectivamente. Ninguém pode optar livremente em nome de quem não pode optar por si próprio, mas a todos compete proteger os interesses de crianças e adolescente de modo vinculado aos valores definidos constitucionalmente.

Não se ignora que, na origem, a constituição também pressupõe escolhas que influenciarão outros além daqueles que a elaboraram, mas essa indagação remonta à própria legitimação do poder estatal, questão que será retomada adiante. Resumidamente, pode-se argumentar que "a legitimidade de uma constituição (ou validade material) pressupõe uma conformidade substancial com a ideia de direito, os valores, os interesses de um povo num determinado momento histórico" (CANOTILHO, 1999, p. 1335).

Por outro ângulo, o direito à educação não é apenas um direito de crianças e adolescentes a serem educados, é o direito que adultos ou idosos têm de ter recebido instrução (SOUSA, 2010, p. 50-51). Ainda que não seja possível vincular a titularidade do direito à educação a um critério etário, a idade é uma referência importante para a inserção nos níveis de ensino. A educação básica é obrigatória entre os quatro e os dezessete anos e deve ser ofertada gratuitamente a quem não teve acesso na idade própria, de acordo com o artigo 208, $\mathrm{I}$, da Constituição Federal. O inciso $\mathrm{V}$ do mesmo artigo diz que os níveis seguintes da

\footnotetext{
${ }^{1}$ A Convenção Sobre os Direitos da Criança é aplicável a todas as pessoas com menos de dezoito anos, como diz seu artigo $1^{\circ}$, assim como o Estatuto da Criança e do Adolescente, que admite excepcional prorrogação até os vinte e um anos incompletos, nos termos de seu artigo $2^{\circ}$, caput e parágrafo único, enquanto a Constituição Federal atribui prioridade também a jovens, o que prorroga a faixa etária abrangida até os vinte e nove anos, conforme $\mathrm{o}$ artigo $1^{\circ}$, parágrafo $1^{\circ}$, da Lei $\mathrm{n}^{\circ} 12.852 / 2013$.
} 
educação devem ser facultados pelo Estado a quem demonstrar aptidão para prosseguir nos estudos e não faz referência a idade. A garantia do direito à educação ao longo da vida foi incluída como princípio estruturante do ensino pela Emenda Constitucional n ${ }^{\circ} 108$ de 2020.

Se já foi estabelecido que o direito à educação é dos educandos, convém esclarecer que qualquer pessoa pode estar nessa condição. Tanto as normas internacionais como o ordenamento interno prezam por uma concepção de educação acessível a todos, independentemente de circunstâncias pessoais.

Quanto ao objeto, seguindo orientação comum às normas internacionais e à Constituição brasileira, o direito à educação compreende o acesso à instrução em nível suficiente para que o educando se desenvolva como pessoa, o que vai além da absorção de conteúdo curricular tradicional e inclui o aprimoramento das habilidades sociais, o contato com a cultura, a promoção da autonomia e o respeito à pluralidade, entre outros aspectos de uma formação humanística. A Constituição Federal de 1988 faz menção também às finalidades de preparar para o exercício da cidadania e de qualificar para o trabalho, que, na verdade, também estão compreendidas no processo de desenvolvimento.

É direito “à liberdade de aprender e de aprender com liberdade" (MONTEIRO, 2003, p. 780), pois a educação submissa, tolhida por ideologia ou religião, redunda em doutrinação ou proselitismo. O conteúdo transmitido deve ser adequado ao nível de desenvolvimento psicológico dos alunos, mas não restringido por critério político. Ao contrário do que supõem iniciativas, a exemplo do movimento Escola Sem Partido, que pretendem vedar conteúdos e abordagens pedagógicas que remetam a orientações políticas, a própria concepção de que é possível eliminar os componentes políticos do conhecimento já é, em si, intensamente ideológica, assim como a proposta de eliminar componentes curriculares somente tem lugar dentro de determinados marcos ideológicos. O que, por outro lado, não significa negar que a educação tem sido instrumentalizada pela política ao longo da História, sobretudo, a partir do século XVIII e com grande influência de Rousseau, como reconhece Hannah Arendt (1972, p. 224). É justamente por essa razão que a forma de lidar com a questão não pode limitar-se à substituição de uma agenda política por outra, que, igualmente, instrumentalizará a educação.

Aprende-se com liberdade quando há a contraposição de ideias, a diversidade de perspectivas, o debate racional e informado, o respeito ao aluno como sujeito que recebe, por meio do ensino, ferramentas que o auxiliam na interpretação do conhecimento que lhe é apresentado, em postura oposta à que o considera depósito das ideias dos educadores. A liberdade na atividade de ensinar e como vetor que orienta o que e como se ensina é essencial 
para que os educandos possam atingir a condição de agentes, tornando-se capazes de orientar suas próprias vidas e influenciar as escolhas do meio em que vivem. A relação entre desenvolvimento e liberdade é constitutiva e instrumental, sendo a liberdade uma forma de desenvolvimento e um meio para alcançá-lo (SEN, 2010, p. 55).

Sendo um direito social, o direito à educação está vinculado à proibição do excesso e da proteção insuficiente (RANIERI, 2009, p. 282). Desdobra-se em direitos a prestações específicas, com graus de exigibilidade diferentes, como o direito público subjetivo ao acesso ao ensino fundamental, cuja negação sujeita os gestores públicos à responsabilização, e o direito a que sejam fornecidas as condições para que o aluno permaneça na rede de ensino, o que inclui a oferta de material escolar e alimentação.

Essas exigências são direcionadas a alguém. O direito à educação pode ser oposto ao Estado, à família, à sociedade, à Comunidade Internacional e até mesmo a cada ser humano, que tem o dever de educar-se "para com a sua dignidade e perfectibilidade, assim como para com a(s) comunidade(s) a que pertence, na medida da sua capacidade de responsabilidade" (MONTEIRO, 2003, p. 770). A Constituição Federal menciona a colaboração da sociedade para a promoção e incentivo da educação, mas como não é possível exigir algo da sociedade como um todo, desprovida de personalidade que é, a exigência recai sobre quem a representa: o Estado. Não obstante seja por meio da família que se inicia a educação e de estarem os responsáveis obrigados a assegurar a matrícula das crianças e adolescentes, é o Estado quem tem a função primordial de assegurar a eficácia dos direitos fundamentais. Não se pode confundir a possibilidade de o ensino ser ministrado em instituições particulares com alguma margem para que o Estado transfira sua responsabilidade de concretizar os direitos previstos na constituição (MONTEIRO, 2003, p. 779).

O conflito entre as pretensões da sociedade a prestações positivas e a limitação dos meios materiais disponíveis para tanto é uma característica comum aos direitos sociais. Dada a centralidade do direito à educação como direito que amplia o acesso a outros direitos, a Constituição Federal diminuiu a margem de discricionariedade dos gestores quanto ao volume de investimento, dedicando atenção ao custeio do ensino ao estabelecer percentuais mínimos da receita dos impostos que devem ser aplicados com essa finalidade pelos entes federados.

Em relação aos meios de proteção, a primeira barreira contrária ao esvaziamento do direito à educação é a conformidade entre as normas internacionais e a ordem interna, de modo conferir-lhe exigibilidade jurídica perante o Poder Judiciário local e, como último recurso, no Sistema Internacional de Direitos Humanos (MONTEIRO, 2003, p. 770-771). 
No exemplo brasileiro, a subdivisão do direito à educação em vários direitos específicos no próprio texto constitucional, além do detalhamento oferecido pelo Estatuto da Criança e do Adolescente e pela Lei de Diretrizes e Bases, torna mais claras as prestações que podem ser exigidas judicialmente, seja pelos indivíduos ou por quem detém legitimidade para pleitear direitos coletivos no sentido amplo. Na via judicial ou extrajudicial, mas sempre por uma perspectiva jurídica, tem destaque o papel que pode ser exercido pelo Ministério Público e pela Defensoria Pública na defesa do direito à educação. Mas não apenas a atuação propriamente jurídica contribui para aumentar a eficácia do direito, órgãos administrativos como os Conselhos de Educação e os Conselhos Tutelares exercem funções necessárias à concretização das normas constitucionais, como a definição de diretrizes para as políticas públicas educacionais e a fiscalização da permanência de crianças e adolescentes na escola.

De modo mais específico, a Constituição Federal prevê, no artigo 208, § $2^{\circ}$, que a autoridade competente será responsabilizada caso não garanta o direito subjetivo público ao ensino obrigatório. A Lei $\mathrm{n}^{\circ}$ 8.069, de 1990, em seu artigo 55, estabelece a obrigação dos responsáveis de matricular crianças e adolescentes na rede regular de ensino, enquanto a Lei $\mathrm{n}^{\circ} 9.394$, de 1996 , no artigo $6^{\circ}$, tem dispositivo semelhante, que torna obrigatória a matrícula a partir dos quatro anos de idade, ambas em conformidade com o artigo $208, \S 3^{\circ}$ da Constituição. No Código Penal, no artigo 246, há a previsão do crime de abandono intelectual, que se configura quando o responsável deixa de prover a instrução primária para a criança em idade escolar.

O direito humano e fundamental à educação é, enfim, o direito do educando a uma educação orientada para seu desenvolvimento e pode ser exigido judicial e administrativamente, com primazia e nessa ordem, do Estado e da família.

\section{A MEDIAÇÃO CONSTITUCIONAL DA RELAÇÃO ENTRE INDIVÍDUO E COLETIVIDADE}

O problema subjacente à aceitação ou não da educação domiciliar - e ao modo como seria possível praticá-la - é a tensão entre indivíduo e coletividade, privado e público, pretensões de isolamento e de intervenção. Saindo do geral em direção ao específico, o ponto inicial da análise é a genealogia do pensamento ocidental acerca da vida dos homens entre outros homens segundo Hannah Arendt, em A Condição Humana (2007), com passagem pela descrição dos fundamentos do poder estatal como elemento central da intermediação das 
relações coletivas no Estado moderno, culminando no neoconstitucionalismo e na constitucionalização de esferas da vida humana que vão além da política.

Há três atividades da vida humana que representam as suas condições: o labor, o trabalho e a ação. O labor corresponde às atividades desenvolvidas com o objetivo essencial da sobrevivência, enquanto o trabalho compreende as atividades destinadas à produção de algo artificialmente pelas mãos humanas. Mais relevante para o problema enfrentado é a ação, que se refere às atividades exercidas pelos homens entre si, necessariamente plurais que são. A ação remete à política, mas nela não se encerra, pois abrange qualquer interação entre diferentes seres humanos (ARENDT, 2007, p. 15).

Entre os gregos antigos, a política era a participação na organização da vida dos homens entre outros homens por meio do discurso e jamais pela violência, que era uma característica das relações pré-políticas que se desenvolviam na esfera privada (ARENDT, 2007, p. 35). Havia, então, um abismo entre o público e o privado. Apenas na modernidade ganhou relevância o reconhecimento de uma esfera social, que não é privada, como a família, nem pública no mesmo sentido específico que a política assumia na pólis grega. A sociedade moderna é um conjunto de famílias economicamente organizadas para emular uma grande família e apresentar-se como nação. Na Grécia antiga, o que fosse relacionado à sobrevivência - a exemplo da economia, tema de importância crescente até vir a ser onipresente no debate público contemporâneo - não era de interesse da política, mas, sim, assunto doméstico (ARENDT, 2007, p. 37-38).

Com a modernidade, a sociedade passa a reivindicar a limitação do poder político para preservar sua liberdade, ao mesmo tempo em que reivindica do Estado que o proteja da violência praticada pelos outros homens. Já a política da pólis grega era o espaço em que poderia ser desenvolvida a excelência, caracterizava-se pela liberdade dos cidadãos - que agiam politicamente entre iguais, no sentido específico de não haver hierarquia entre si -, de modo que os conceitos de domínio, submissão, governo e poder eram vinculados à esfera privada e passaram à pública apenas com a modernidade (ARENDT, 2007, p. 40-41). Na ordem de ideias anterior, o poder político nunca poderia ser total e inquestionável como o poder familiar. O modo de exercer o poder na família era incompatível com a política dos antigos, que era necessariamente condicionada pela interação entre iguais e, assim, não se conciliava com o poder virtualmente ilimitado que veio a ser deferido ao soberano por Thomas Hobbes (ARENDT, 2007, p. 37). 
Sob o Estado moderno, o abismo entre as esferas pública e privada deixa de existir. A política passa a ser uma função da sociedade, a economia deixa de ser uma atividade essencialmente doméstica, o que antes pertencia exclusivamente ao domínio privado é permeado pelo interesse público (ARENDT, 2007, p. 42). Se antes o privado existia em oposição ao político, passa a se constituir em oposição ao social. A esfera privada era aquela em que se desenvolviam as atividades do labor e do trabalho, era responsável, em suma, por cuidar do que era necessário para viver. Quando essas questões passam para a esfera pública, resta ao domínio privado a preservação da intimidade (ARENDT, 2007, p. 48).

“A sociedade é a forma na qual o fato da dependência mútua em prol da subsistência, e de nada mais, adquire importância pública, e na qual as atividades que dizem respeito à mera sobrevivência são admitidas em praça pública" (ARENDT, 2007, p. 56). Foi o Estado moderno quem levou a política ao terreno da necessidade. Por ser necessária a atuação estatal, estava justificado o contrato social que a autorizava e a função do direito nesse novo arranjo foi sendo consolidada e expandida, até passar a qualificar o Estado. A compreensão da forma como o poder estatal é exercido e do papel desempenhado pela constituição na fundamentação e legitimação dessa atividade passa necessariamente pelos marcos teóricos do Estado moderno, que não chegam a compor uma teoria única, mas são constituídos das obras de diferentes pensadores que, cada um a seu modo, abordou o problema em questão, contribuindo para a aproximação entre a política e o direito por meio da racionalidade.

Maquiavel, no século XVI, além de rejeitar a fundamentação religiosa para o exercício do poder, entendia que a fraqueza do povo de seu tempo e lugar era derivada do Cristianismo, com sua característica de desprezo pelo mundo material. Concedeu à religião, então, um papel instrumental na manutenção da postura submissa dos governados, mas não constituinte do poder (MORRISON, 2006, p. 88).

Outro fundamento haveria de existir para justificar o poder, de modo a evitar a dispersão dos indivíduos na defesa de seus interesses imediatos. A descrição dessa justificativa em termos racionais é o que se extrai de mais relevante e duradouro da obra de Thomas Hobbes. A legitimidade do soberano, no pensamento hobbesiano, assenta-se nas funções que desempenha, mais precisamente, na defesa da paz e da unidade social, em oposição à anarquia que Hobbes supunha que existiria no estado de natureza. Se o Estado é necessário para uma finalidade que pode ser identificada pela razão, está posto o seu fundamento laico. 
Na perspectiva de Hobbes, os súditos cedem seus direitos individuais ao soberano, trocam independência e liberdade por segurança e paz, ao fazê-lo, estabelecem um pacto, que pressupõe que os demais indivíduos cedam igualmente e, com isso, outorguem ao soberano o direito de representá-los (SOARES, 2001, p. 94). O súdito, pelo pacto de união que cede o direito de representação, passa a ser coautor de cada ato do soberano, não podendo, por esse motivo, questionar a justeza de seus atos (SOARES, 2001, p. 97). Legitimado pelo contrato social, o soberano concentrava todas as funções públicas, incluindo as executivas, legislativas, judiciárias e religiosas, e estava comprometido apenas com a garantia da paz que justificava sua existência, mas como "o poder é a essência da questão, o soberano não pode sujeitar-se à lei”. (MORRISON, 2006, p. 112). Hobbes deixou de enfrentar os problemas que derivam do exercício do poder ilimitado e a sua concepção de Estado veio a ser superada pelo Estado constitucional, que começa a se formar com a Revolução Gloriosa (SOARES, 2001, p. 9899).

John Locke adotou a defesa da propriedade como função primordial do Estado, mas limitou ao exercício do poder ao colocar o Poder Legislativo como barreira ao absolutismo. O Poder Executivo deveria obedecer às leis, mas tinha margem de discricionariedade para buscar o bem comum (SOARES, 2001, p. 104). A legitimidade para a identificação do bem comum é um problema que Jean Jacques Rousseau procurou enfrentar por meio da ideia de que as leis deveriam corresponder à vontade geral, obrigando, inclusive, o príncipe. $\mathrm{O}$ soberano, no Estado rousseauniano, teria identidade com o povo e, assim, era rejeitado o sistema de representação, o que limitava a aplicação prática desse projeto a comunidades políticas pequenas (SOARES, 2001, p. 117). Se havia identidade entre povo e soberano, a legitimidade das ações estatais prescindia de demonstração. Mas Rousseau se absteve de oferecer uma solução para a identificação da vontade geral em um local onde não fosse possível a participação direta do povo na formulação das leis, abrindo margem para que suas ideias insuflassem posturas tirânicas de quem diz falar em nome da vontade geral, como no período do Terror da Revolução Francesa.

A relevância da lei como instrumento de proteção contra o exercício do poder sem limites é progressivamente construída pelas ideias contratualistas e, com Montesquieu, culmina na descrição do funcionamento das funções executiva, legislativa e judiciária por meio de um sistema de freios e contrapesos. Inobstante Montesquieu não tenha utilizado o contrato social para fundamentar sua concepção de Estado e tampouco seja o autor original da 
ideia de separação de poderes - que já estava na obra de Platão -, sua análise e sua proposta influenciaram o constitucionalismo a ponto de se tornar um dogma (SOARES, 2001, p. 111).

A estruturação do Estado por meio das leis não foi suficiente para evitar a tirania. $\mathrm{O}$ horror do totalitarismo da primeira metade do século XX levou à preponderância de um modo de organizar o Estado que tem na constituição o seu ponto central e recebe a nomenclatura de constitucionalismo, descrito por Canotilho (1999, p. 47) como "teoria (ou ideologia) que ergue o princípio do governo limitado indispensável à garantia dos direitos em dimensão estruturante da organização político-social de uma comunidade”. De inspiração iluminista, o constitucionalismo reconhece o valor dos indivíduos como sujeitos de direitos e garante-lhes uma esfera de autonomia que não pode ser invadida pelo poder (CANOTILHO, 1999, p. 107). Por outro lado, chama os indivíduos para a esfera social ao atribuir-lhes, também, o dever de observar os direitos fundamentais mesmo quando não são eles próprios seus beneficiários em uma situação concreta, estabelecendo uma eficácia horizontal para os direitos, em oposição à eficácia vertical que se verifica quando a relação se dá entre o soberano e o súdito, ou entre o Estado e o cidadão (CANOTILHO, 1999, p. 1206).

A constituição se situa na esfera intermediária entre o público e o privado que é a sociedade, admitindo intervenções do Estado sobre os indivíduos, desde que condicionadas pelos direitos fundamentais que são de todos e de cada um. Assim como o Estado moderno tinha seu poder justificado pelas funções que exercia, o Estado constitucional encontra sua legitimidade em uma principiologia afinada com os valores de um povo e de um lugar, mas, com a preocupação de evitar a tirania, confere proteção às minorias contra maiorias totalizantes. Além das prerrogativas que têm as minorias parlamentares, com seu poder de obstrução, a tutela das minorias no cotidiano da sociedade ficou a cargo do Judiciário, cuja corte mais alta é frequentemente chamada a exercer função contramajoritária, opondo-se ao conteúdo dos atos de quem age com apoio popular (BARROSO, 2005, p. 47).

O constitucionalismo se aproximou da democracia e levou a constituição a ter efetiva força normativa, irradiando influência sobre todo o ordenamento jurídico, que deve estar em conformidade com os valores constitucionais. Ainda na década de 1950, Konrad Hesse (1991, p. 19) sustentou que embora a constituição não possa agir por si própria, pode ordenar e, se as ordens são cumpridas, adquire força ativa. No Brasil, a incorporação dessa concepção é mais tardia e decorre da ordem estabelecida pela Constituição Federal de 1988, recebendo a denominação de neoconstitucionalismo (BARROSO, 2005, p. 4). 
Paralelamente à criação de um Sistema Internacional de Direitos Humanos a partir da Declaração Universal dos Direitos do Homem de 1948, nas ordens internas o foco da preocupação foi deslocando-se gradualmente do reconhecimento para a eficácia dos direitos fundamentais. O rol de direitos previsto na constituição deixa de ser uma carta de intenções e constitui a baliza a ser seguida por todo o ordenamento, cujas leis específicas devem assumir o compromisso de concretizá-los. O processo de constitucionalização de todo o ordenamento jurídico impõe limites e deveres ao Poder Legislativo e à Administração Pública, constitui a baliza hermenêutica preponderante do Judiciário, a quem incumbe o controle de constitucionalidade em todas as instâncias (BARROSO, 2005, p. 17). Como consequência da colocação dos direitos fundamentais na ordem do dia, houve um processo de judicialização de questões que anteriormente eram restritas ao Legislativo e ao Executivo, a exemplo da própria matéria apreciada no Recurso Extraordinário nº 888.815 (BARROSO, 2005, p. 45).

A ampliação da zona de influência da constituição constitui uma marca do Estado Constitucional de Direito. A constitucionalização do direito chegou à educação, limitando a liberdade do legislador ordinário, proibindo o arbítrio na matéria, e, em razão da eficácia horizontal, alcançando também os particulares, que não podem agir de modo a comprometer a concretização de um direito fundamental (RANIERI, 2009, p. 331).

A nítida separação entre o público e o privado que havia entre os antigos não é mais possível desde a ascensão da sociedade na modernidade como instância intermediária em que problemas antes domésticos foram tornados públicos. O Estado moderno assumiu um modo hierárquico de exercer o poder na esfera pública que antes era dado apenas aos chefes das casas; para fazê-lo, precisava justificar o exercício do poder na necessidade. Em resposta a experiências históricas totalitárias e tirânicas, a atuação estatal necessária assumiu contornos específicos derivados da centralidade da constituição para a organização da vida em sociedade e do consequente compromisso com os direitos fundamentais.

\section{OS PROJETOS DE LEI N ${ }^{\circ}$ 3179/2012, 2401/2019 E 3262/2019}

A tentativa de regulamentar a educação domiciliar no Brasil é anterior ao julgamento do Recurso Extraordinário ${ }^{\circ} 888.815$ pelo Supremo Tribunal Federal (2019), ocasião em que ficou consignada no acórdão respectivo a ausência de incompatibilidade em tese entre a prática e a Constituição Federal de 1988. Há quase uma década, tramita o projeto de lei $\mathrm{n}^{\circ}$ $3179 / 2012$, a que está apensado o projeto de lei n 2401/2019. 
Mais recentemente, merece destaque o projeto de lei $n^{\circ} 3262 / 2019$, que, por ter conteúdo mais restrito e estar pronto para ser incluído na pauta do Plenário, será analisado em primeiro lugar. É de autoria das deputadas federais Chris Tonieto (PSL/RJ), Bia Kicis (PSL/DF) e Caroline de Toni (PSL/DF) e do deputado federal Dr. Jadiel (PL/CE). Consiste na inclusão de parágrafo único no artigo 246 do Código Penal, para que seja expressamente atípica a conduta de instruir crianças e adolescentes em idade escolar por meio da educação domiciliar.

A justificação do projeto ignora o conhecimento acumulado a respeito do direito à educação e, do texto constitucional, aproveita apenas os excertos que o favorecem. A finalidade da educação seria desenvolver a sabedoria e promover o "fim último do homem, que é a contemplação da Verdade" (BRASIL, 2019b). Pressupõe-se, então, que há uma verdade única cuja identificação e transmissão correspondem às tarefas principais da educação, em posição contrária à pluralidade assentada constitucionalmente.

A educação domiciliar seria um "direito dos pais, por Lei Natural" (BRASIL, 2019b), sem que seja especificado o que se entende por tal. Dessa lei natural supostamente aceita por todos os povos, decorreria que "até mesmo a vontade dos filhos pertence, antes da idade da razão, aos seus pais" (BRASIL, 2019b). São sobrepujadas todas as nuances que levam à compreensão de que o "direito à educação não é um direito dos pais sobre os filhos, nem do Estado sobre os cidadãos. É um direito dos filhos e dos cidadãos às responsabilidades dos pais e do Estado para com o seu direito à educação" (MONTEIRO, 2003, p. 786). Há a inversão da lógica quando se argumenta que é o Estado quem impede a educação integral, oferecendo-a apenas parcialmente. Sem explicação, parte-se da premissa de que mais completa é a instrução fornecida no domicílio, sem contato com outras perspectivas.

A proposta chega a argumentar que a educação não "pode ter como fim o trabalho, a especialização" (BRASIL, 2019b), em sentido exatamente oposto ao que diz o artigo 205 da Constituição Federal de 1988, que coloca com uma das finalidades da educação a qualificação para o trabalho. Caso aprovada, a norma colocaria o ensino domiciliar em uma zona cinzenta, seria rejeitada a sua proibição, mas, ao mesmo tempo, ainda não seria textualmente autorizada e regulamentada a prática como recomendou o Supremo Tribunal Federal.

O projeto de lei $\mathrm{n}^{\circ} 3179 / 2012$, de autoria do deputado federal Lincoln Portela (PR/MG), apenas acrescenta o $\S 3^{\circ}$ ao artigo 23 da Lei $n^{\circ} 9.394 / 1996$, para autorizar expressamente a educação básica domiciliar, submetida à supervisão dos órgãos que compõem o sistema educacional. Não regulamenta, mas apenas autoriza. A sintética 
justificação menciona a intenção de "reconhecer o direito de opção das famílias com relação ao exercício da responsabilidade educacional para com seus filhos" (BRASIL, 2012) e argumenta que a matéria foi apresentada por respeito à liberdade. Sem embargo de que uma fundamentação exígua possa ser precisa, o que se vê nesse caso são fórmulas superficiais que não respondem às questões suscitadas pela educação domiciliar, em especial, a falta de convívio social e a ausência de pluralidade.

A proposta de regulamentação está no projeto de lei $n^{\circ}$ 2401/2019, de iniciativa do Poder Executivo, que, em dezessete artigos, "dispõe sobre o exercício do direito à educação domiciliar" (BRASIL, 2019a) e, para tanto, modifica as Leis $\mathrm{n}^{\circ}$ 8.069/1990 e 9.394/1996. Parte do pressuposto, assim, de que há um direito à educação domiciliar, embora não explique a origem ou conteúdo de tal direito.

Esse projeto reproduz trechos do texto constitucional, mas não lhes empresta concretude. Fala-se na Constituição Federal, mas são definidas regras que não levam em conta seu conteúdo, redundando em jogo retórico. Ao entrar em detalhes, a minuta prevê a "plena liberdade de opção dos pais ou dos responsáveis legais entre a educação escolar e a educação domiciliar" (BRASIL, 2019a), vedando a modalidade apenas aos que estejam cumprindo pena por crimes previstos no Estatuto da Criança e do Adolescente, na Lei Maria da Penha, no Título VI do Código Penal, na Lei de Entorpecentes e na Lei de Crimes Hediondos. Mais uma vez, os pais são confundidos com os titulares do direito à educação. Essa posição autoriza implicitamente que a ideologia dos responsáveis legais seja o único fator determinante da modalidade de ensino a ser ministrada.

Há a preocupação em assegurar isonomia entre estudantes de ambas as modalidades no sentido de que tenham acesso a concursos públicos, competições e avaliações nacionais e internacionais. Contudo, a isonomia no acesso à pluralidade de perspectivas, se muito, existe apenas no dever dos pais ou responsáveis de assegurar a convivência comunitária, enunciado sem qualquer detalhamento. A minuta institui avaliações anuais promovidas pelo Ministério da Educação, com possibilidade de aplicação de provas de recuperação, às quais deverão submeter-se os educandos em regime domiciliar. Prevê, confundindo o direito com seu exercício, que ocorrerá a perda do "exercício do direito à opção pela educação domiciliar" (BRASIL, 2019a), em casos de reprovações na avaliação pública, sem estabelecer hipóteses em que a prática poderia ser retomada, o que indica uma provável judicialização do tema caso o projeto venha a ser aprovado. 
De resto, a proposta adapta dispositivos do Estatuto da Criança e do Adolescente e da Lei de Diretrizes e Bases da Educação Nacional, além de indicar os caminhos burocráticos que devem ser seguidos por quem optar pela educação domiciliar, mas autoriza o início da instrução em casa independentemente da implementação do sistema por meio do qual seria exercido o controle da atividade. A justificação do projeto revela que foram ouvidos em sua elaboração especialistas e técnicos, mas não apresenta seus nomes; nomeia apenas entidades de defesa do ensino domiciliar que colaboraram e menciona entrevistas com famílias adeptas da prática mesmo antes de sua regulamentação. A lei, assim, é concebida por quem não segue o ordenamento jurídico. Quanto à persecução das finalidades da educação assentadas na Constituição Federal, oferece como resposta apenas a submissão dos educandos a exame nacional. Na parte da justificativa que trata do aspecto material da proposta e mal preenche duas laudas, não há qualquer menção à pluralidade de perspectivas e a uma educação voltada para os direitos humanos. O restante do texto procura demonstrar a relevância e a urgência da matéria que ensejam sua tramitação como medida provisória.

Não há qualquer preocupação com condições objetivas em que o ensino domiciliar pode decorrer da necessidade, como nas hipóteses de especiais dificuldades de acesso e manutenção na rede regular de ensino experimentadas, respectivamente, por famílias que vivem em áreas isoladas e pela comunidade circense. A livre escolha dos pais ou responsáveis é o único critério adotado, em uma visão extremada da liberdade, que a defere aos que se colocam como educadores com exclusividade, ao mesmo tempo em que a nega aos educandos. As impressões digitais de uma ideologia contrária à democrática variação de perspectivas são avistáveis a olho nu.

$\mathrm{O}$ modelo proposto é insuficiente. $\mathrm{O}$ direito à educação fundamental obrigatória não é direito apenas ao ensino, mas também a que o ensino seja ministrado em estabelecimento adequado e de acordo com os parâmetros constitucionais. A liberdade de optar entre concepções pedagógicas é limitada às escolhas disponíveis na rede regular de ensino, com suas variações de orientações nos métodos e na eventual inclinação religiosa (RANIERI, 2009, p. 345-346). Ainda que seja superada essa concepção restritiva e a educação domiciliar seja admitida como uma hipótese válida de método pedagógico, a falta que a escola faz não se resolve pelo desprezo ao problema.

Os estabelecimentos regulares de ensino são espaços privilegiados para a realização da educação em sentido amplo, em que a prevalência dos interesses dos legítimos titulares do direito à educação pode ser sopesada pelos diferentes atores do sistema educacional, 
equalizando-se as pretensões do Estado, da família e da sociedade. A escola se coloca entre a família e o mundo, para que seja possível fazer a transição do privado para o público (ARENDT, 1972, p. 237). A existência dessa zona intermediária é necessária, pois nem “a educação nem a engenhosidade nem o talento pode substituir os elementos constitutivos da esfera pública, que fazem dela o local adequado para a excelência humana" (ARENDT, 2007, p. 59). O acesso controlado de crianças e adolescentes à vida pública, por meio da escola, que é um ambiente adequado para tanto, permite que sejam vistos e ouvidos por outros, que veem e ouvem cada um a seu modo, em processo de enriquecimento mútuo das suas existências. "É este o significado da vida pública, em comparação com a qual até mesmo a mais fecunda e satisfatória vida familiar pode oferecer somente o prolongamento ou a multiplicação de cada indivíduo, com os seus respectivos aspectos e perspectivas" (ARENDT, 2007, p. 67).

O ambiente escolar é, ainda, um espaço garantidor dos direitos de crianças e adolescentes, que desempenha relevante papel na rede de proteção (BORGES, 2021, p. 196). $\mathrm{Na}$ escola tem lugar o debate, a promoção dos direitos humanos, em contraponto "a um modelo educacional imposto ou estatuído por pequenos grupos ou pais ansiosos por um 'melhor' para seus filhos, que pode não corresponder ao verdadeiro sentido da educação" (VERONESE; ROSSETTO, 2021, p. 89).

Em comum, todos os projetos de lei analisados desconsideram a pluralidade como um princípio informador da educação e ignoram a importância da escola para a formação em aspectos que transcendem a transmissão de conteúdo curricular. Ao menos, não é empreendido qualquer esforço para esconder o caráter fortemente ideológico das intenções que permeiam os projetos. O lampejo de honestidade intelectual, no entanto, não é suficiente para suprir a falta de conformidade com a Constituição Federal de 1988, que, situada no neoconstitucionalismo, não admite a formulação de leis como ilhas apartadas dos valores centrais do ordenamento.

\section{CONCLUSÃO}

O direito à educação é individual e coletivo, situa-se tanto na esfera privada como na pública; é do educando, mas repercute na sociedade. É direito humano e também fundamental, que, mais do que estar previsto na Constituição Federal de 1988, dela retira os valores que o informam, condicionando todo o ordenamento jurídico. O modo de exercê-lo em um Estado Constitucional de Direito, portanto, não é da alçada exclusiva dos indivíduos. 
A defesa de uma separação intransponível entre o doméstico e o público encerra valores superados desde o advento do Estado moderno, cujos teóricos, concomitantemente à criação de mecanismos de proteção dos indivíduos contra o poder estatal ilimitado, justificaram a legitimidade do exercício do poder nas necessidades da sociedade. Assim, o necessário à sobrevivência deixa de ser assunto privado e ganha a praça pública. A intervenção do Estado em áreas antes por ele intocadas é ampliada, reclamando um paradigma jurídico que equacione a tensão entre público e privado, com pretensão de legitimidade extraída da identificação axiológica entre seu suporte normativo e seus destinatários.

Dos valores que despontaram no plano internacional após a Segunda Guerra Mundial, o respeito à pluralidade ganha particular importância quando transposto para a educação, por ser condição para que convivam em harmonia as dimensões pública e privada do direito humano correspondente. No Brasil, estabelecido como fundamental, o direito à educação tem conteúdo extraído do texto constitucional incompatível com perspectivas totalizantes. É notório que a própria opção por uma educação voltada para os direitos humanos é carregada de valores e, desse modo, em alguma medida, é ideológica. Nada há de errado com a ideologia em princípio. Canotilho (1999, p. 47) chega a caracterizar o constitucionalismo como uma ideologia. Mas uma ideologia que se pretenda suficiente e rejeite o contraditório não é compatível com a Constituição Federal de 1988, ou com qualquer constituição democrática.

O risco de que o ensino domiciliar enverede por esse caminho é grande demais para ser ignorado e não precisa ser presumido, já que foi confessado pela parte que levou a questão ao Supremo Tribunal Federal e, em uma leitura embasada teoricamente, é extraído das justificações dos projetos de lei que intencionam regulamentar a matéria. No Recurso Extraordinário $\mathrm{n}^{\circ} 888.815$, a pretensão era fundada em uma alegada incompatibilidade entre as concepções da parte autora e o ensino ministrado pelo Estado. Nos projetos de lei analisados, é indisfarçável uma visão do direito à educação que não tem correspondência na Constituição Federal.

O que se extrai das propostas de regulamentação da educação domiciliar no Brasil é que, ao fim, confundem o capricho ideológico com um suposto e jamais fundamentado direito natural absoluto que os pais ou responsáveis teriam sobre a educação de crianças e adolescentes em idade escolar. É muito menos do que o necessário para excepcionar o direcionamento oferecido pelo regime constitucional do direito à educação. 


\section{REFERÊNCIAS}

ARENDT, Hannah. A crise na educação. Entre o passado e o futuro. São Paulo: Perspectiva, 1972, p. 221-247.

ARENDT, Hannah. A condição humana. $10^{a}$ ed. Rio de Janeiro: Forense Universitária, 2007.

BARROSO, Luiz Roberto. Neoconstitucionalismo e Constitucionalização do Direito. Revista de Direito Administrativo, v. 240, 2005.

BRASIL, Constituição da República Federativa do Brasil de 1988. Disponível em: http://www.planalto.gov.br/ccivil_03/constituicao/constituicaocompilado.htm. Acesso em: 27 mai. 2021.

BRASIL. Câmara dos deputados. Projeto de lei ordinária n 3179/2012. Disponível em: https://www.camara.leg.br/proposicoesWeb/prop_mostrarintegra?codteor=963755\&filename $=\mathrm{PL}+3179 / 2012$. Acesso em: 23 jun. 2021.

BRASIL. Câmara dos deputados. Projeto de lei ordinária nº 2401/2019. 2019a. Disponível em:

https://www.camara.leg.br/proposicoesWeb/prop_mostrarintegra;jsessionid=node01 iczygsd8 weqog5rrbrz6debb27047552.node0? codteor $=1734553 \&$ filename $=P L+2401 / 2019$. Acesso em: 23 jun. 2021.

BRASIL. Câmara dos deputados. Projeto de lei ordinária n 3262/2019. 2019b. Disponível em:

https://www.camara.leg.br/proposicoesWeb/prop_mostrarintegra?codteor=1759042\&filenam e=PL+3262/2019. Acesso em: 23 jun. 2021.

BRASIL. Supremo Tribunal Federal. Recurso Extraordinário n ${ }^{\circ}$ 888.815. Relator Ministro Roberto Barroso. Relator para o acórdão Ministro Alexandre de Moraes. Brasília, 12 de setembro de 2018. Diário da Justiça eletrônico n 55, 20 mar. 2019.

BORGES, Gláucia. Para além do ensino: as escolas como ambientes concretizadores dos direitos fundamentais de crianças e adolescentes. In: VERONESE, Josiane Rose Petry; BRITO, Rafaela Silva; FONSECA, Reynaldo Soares da (org.). A educação e o direito: a construção de uma sociedade fraterna. Caruaru, Editora Asces, 2021.

CANOTILHO, José Joaquim Gomes. Direito Constitucional e Teoria da Constituição. $3^{\text {a }}$ ed. Coimbra: Almedina, 1999.

HESSE, Konrad. A Força Normativa da Constituição. Tradução: Gilmar Ferreira Mendes. Porto Alegre: Sergio Antonio Fabris Editor, 1991.

MONTEIRO, Agostinho dos Reis. O pão do direito à educação. In: Revista Educação \& Sociedade, vol. 24, n. 84, p 763-789. Campinas: CEDES - Unicamp, 2003. Disponível em: 
https://www.scielo.br/j/es/a/fWQx4RNKtZZw93cvmN4Qyzr/?lang=pt\&format=pdf. Acesso em: 05 jun. 2021.

MORRISON, Wayne. Filosofia do Direito: dos gregos ao pós-modernismo. São Paulo: Martins Fontes, 2006.

RANIERI, Nina Beatriz Stocco. O Estado Democrático de Direito e o sentido da exigência de preparo da pessoa para o exercício da cidadania, pela via da educação. Tese (livre docência) - Departamento de Direito do Estado. Faculdade de Direito. Universidade de São Paulo. 2009. Disponível em: https://www.teses.usp.br/teses/disponiveis/livredocencia/2/tde10092019-171515/publico/TESE_LIVRE_DOCENCIA_NINA_RANIERI.pdf. Acesso em: 05 jun. 2021.

SEN, Amartya. Desenvolvimento como liberdade. São Paulo: Companhia das Letras, 2010.

SOARES, Mário Lúcio Quintão. Teoria do Estado: o substrato clássico e os novos paradigmas como pré-compreensão para o direito constitucional. Belo Horizonte: Del Rey, 2001.

SOUSA, Eliane Ferreira de. Direito à educação: requisito para o desenvolvimento do país. São Paulo: Saraiva, 2010.

VERONESE, Josiane Rose Petry; ROSSETTO, Geralda Magella de Faria. Desenvolvimento como educação e aptidões em fraternidade: contrapontos em face da tecnologia. In: VERONESE, Josiane Rose Petry; BRITO, Rafaela Silva; FONSECA, Reynaldo Soares da (org.). Educação, direito e fraternidade. Caruaru, Editora Asces, 2021. 